\title{
Prevalence and Concomitancy of Respiratory Viruses in Children with Acute Respiratory Tract Infections
}

\author{
Uğur Tüzüner ${ }^{1}$ Oya Akkaya ${ }^{2}$ Mehmet Özdemir ${ }^{1} \quad$ Muhammet Güzel Kurtoğlu $^{2}$
}

${ }^{1}$ Necmettin Erbakan University, Meram Medical Faculty, Medical Microbiology Department, Medical Virology Division, Konya, Turkey

2 Turkish Ministry of Health Konya Training and Research Hospital, Medical Microbiology Department, Konya, Turkey Address for correspondence Dr. Uğur Tüzüner, MD, Necmettin
Erbakan University, Meram Medical Faculty, Medical Microbiology
Department, Konya, Turkey (e-mail: drugurtuzuner@gmail.com).

J Pediatr Infect Dis 2016;11:1-5.

\begin{abstract}
Keywords

- respiratory tract infections

- children

- viruses

Respiratory tract infections (RTI) are among the most commonly seen infections in children across the world, with the highest rate of morbidity. Viruses are known to be the primary agent in these infections and mostly lead to upper RTIs. The most commonly seen viral agents of RTIs may be listed as rhinoviruses (HRV), influenza, parainfluenza (PIV), respiratory syncytial virus (RSV), adenovirus, and enteroviruses.

In this study, prediagnosed children with acute RTI between January 2013 and May 2015 were included. Nasopharyngeal swab samples obtained from a total of 2,268 patients admitted to the hospital of Meram Medical School of Necmettin Erbakan University and Ministry of Health Konya Training and Research Hospital were investigated.

The nasopharyngeal swab samples obtained in the hospital of Meram Medical School were investigated via Seeplex RV12 ACE Detection multiplex PCR (Seegene, South Korea) while the samples in Konya Training and Research Hospital were assessed using the system by CLART PneumoVir (Genomica, Spain).

Of the 2,268 samples investigated in the study, 1,320 (58.2\%) were detected for viruses. Positive number of viruses found in both kits were collected for use in a table, and the most common viruses rates were calculated according to these numbers. Among positive 1,221 samples, $27.9 \%$ were found to be RSV B, and this rate was, in turn, followed by HRV (18.8\%) and RSV A. The most frequent concomitant of double viral agents was observed in RSV B and HRV as $14 \%$ followed by RSV A and HRV as $6.8 \%$, and PIV 3 and HRV with 5.9\%. While RSV B and RSV A were encountered most in winter and spring months, HRV was determined as an infectious agent in all seasons.

Multiplex polymerase chain reaction is beneficial for physicians to diagnose such viruses at an early stage. By the early detection of respiratory viruses leading to seasonal epidemics, physicians' approach to patients will become easier, and unnecessary use of antibiotics will be prevented. Additionally, our study findings are intriguing in shedding light on studies related to the development and application of vaccines.
\end{abstract}

received

April 19, 2016

accepted after revision

June 8, 2016

published online

August 2, 2016
Copyright $\odot 2016$ by Georg Thieme

Verlag KG, Stuttgart · New York
DOI http://dx.doi.org/ 10.1055/s-0036-1585585. ISSN 1305-7707. 


\section{Introduction}

Respiratory tract infections (RTI) are among the most commonly seen infections across the world, with the highest rate of morbidity. Viruses are known to be the primary agent in 20 to $60 \%$ of these infections and mostly lead to upper RTIs. However, in risk groups such as children, the elderly, those with underlying disorders, and patients with immunosuppression, viruses could lead to serious infections by involving lower respiratory tract, with high mortality. ${ }^{1}$ Virus-induced RTIs are seen as significant public health challenges as they easily lead to epidemics. Acute lower RTIs are reported to cause nearly four million deaths annually, consisting mostly of children under 5 years of age. ${ }^{2}$ In preschool period, each child experiences acute RTIs approximately five to eight times per annum. ${ }^{3}$ The most commonly detected viruses are respiratory syncytial virus (RSV), rhinovirus (HRV), and influenza virus (INF). ${ }^{4}$ The others may be listed as parainfluenza (PIV), adenovirus (AdV), and enteroviruses (EV). Thanks to the developments in molecular diagnostic modalities, in recent years, a number of tests have begun to be used to diagnose viral RTIs, and many novel viruses leading to RTIs have been described, such as human metapneumoviruses (HMPV), severe acute respiratory syndrome coronavirus which causes severe acute respiratory syndrome, human coronavirus $(\mathrm{HCoV})$, HCoV-NL63, HCoV-HKU1, human bocavirus (HBoV), and polyomaviruses KI and WU. Among these agents, while INF, PIV, and RSV lead to epidemics in general, viruses such as AdV, $\mathrm{HCoV}$, and $\mathrm{HRV}$ give rise to endemic infections. ${ }^{1}$

The agents of acute RTIs, viruses, may exhibit different characteristics, depending on geographical regions, seasonal differences, and diagnostic procedures. In warm climates, an increase is observed in the incidences of RSV and INF, especially during winter months. PIV 3 and PIV 1 in winter, PIV 2 at the initial of fall and winter, EV during summer and fall months, and HRV in spring and winter are known to cause infections at a higher rate, while AdVs could be the reason for infections within each season. ${ }^{1}$ PIV seasonality follows type-specific seasonal patterns, with PIV 1 circulating in odd-numbered years and PIV 2 and PIV 3 circulating annually. ${ }^{5}$

Detection and classification of the common respiratory pathogens is impressively important because of the fact that pathogens have potentially high morbidity and mortality rates. Culture-based, antigen-based, and molecular techniques are currently used as diagnostic methods. Among them, molecular methods have the potential for the highest sensitivity, with assay turn-around times on the order of a few hours and foreseeable capability to be run in a high-throughput batch process ${ }^{6,7}$ In multiplex PCR assay ( $\mathrm{MPCR}$ ) with higher sensitivity, resulting in a shorter time and one of the nucleic acid diagnostic methods developed to be used in the rapid diagnosis of respiratory tract pathogens in clinical samples, multiple respiratory viruses can be detected more than once in the same reaction using one clinical sample at the same time. ${ }^{8}$ Especially in children with lower RTI, agents can be diagnosed in exacerbations such as febrile neutropenia, cystic fibrosis and chronic obstructive pulmonary disease, and unnecessary use of antibiotics is prevented. ${ }^{9}$ Because of providing rapid results, MPCR causes morbidity and mortality rates to be decreased. ${ }^{10}$

In the present study designed retrospectively, it was aimed at investigating viral agents leading to acute RTIs and their seasonal distributions in the province of Konya.

\section{Materials and Methods}

\section{The Group of Patients and Clinical Samples}

Prediagnosed with acute RTI between January 2013 and May 2015, children under the age of 18 were included in the study. Nasopharyngeal swab samples obtained from a total of 2,268 patients admitted to the hospital of Meram Medical School of Necmettin Erbakan University and Ministry of Health Konya Training and Research Hospital were investigated.

\section{Method of $\mathbf{M P C R}$}

The nasopharyngeal swab samples obtained from the hospital of Meram Medical School were investigated via Seeplex RV12 ACE Detection mPCR (Seegene, South Korea) while the samples from Konya Training and Research Hospital were assessed using the system by CLART PneumoVir (Genomica, Spain). Although only 12 viral agents such as HMPV, AdV, HCoV; 229E/NL63, and OC43/HKU1, PIV 1, 2 and 3, INF A and $B$, RSV A and B, and HRV A and B could be investigated by the system of Seeplex RV12 ACE Detection mPCR. The system of CLART PneumoVir was capable of determining 18 viruses such as AdV, HMPV A and B, PIV 1, 2, 3 and 4 (A and B subtypes), HRV, RSV A and B, HBoV, HCoV; 229E, OC43, and NL63, EV, INF A (H7N9, H3N2, H1N1, H1N1/2009 subtypes), and INF B, and C (-Figs. 1, 2 and $\mathbf{3}$ ).

\section{Results}

Of the 2,268 samples investigated in the study, viruses were detected as agents in 1,320 (58.2\%). The 1,320 positive samples were composed of 427 men (42.1\%) and 588 women (57.9\%). Positive number of viruses found in both kits were collected for use in a table, and the most common viruses' rates were calculated according to these numbers, among which, $27.9 \%$ were found to be RSV B, and this rate was, in turn, followed by HRV (18.8\%) and RSV A (17.8\%) (- Table 1).

Positivity was detected in agents more than once in 263 of 2,268 respiratory tract swap samples in the study, and the findings presented in - Table $\mathbf{2}$.

The most frequent concomitancy of double agents was observed in RSV B and HRV with $14 \%$ followed by RSV A and HRV with 6.8\%, and PIV 3 and HRV with 5.9\% (-Table 3).

Considering the distribution of samples with positivity to months, the positivity was observed to be densely accumulated in January, February, March, and April (-Table 4).

While RSV B and RSV A are encountered most in winter and spring months, HRV was determined as an infectious agent in all seasons ( - Table 5 ). 


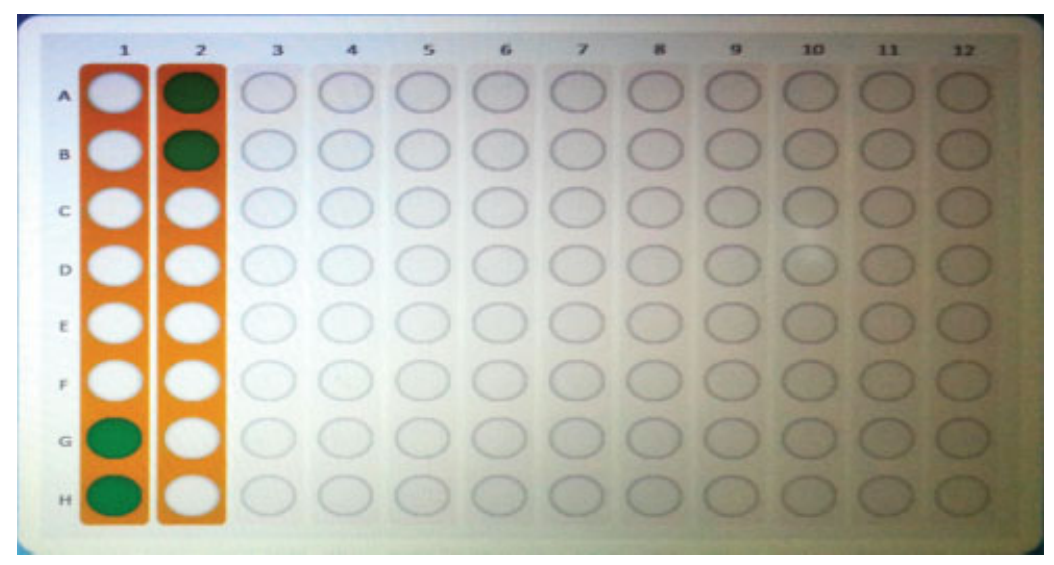

Fig. 1 Patients' panel studied.

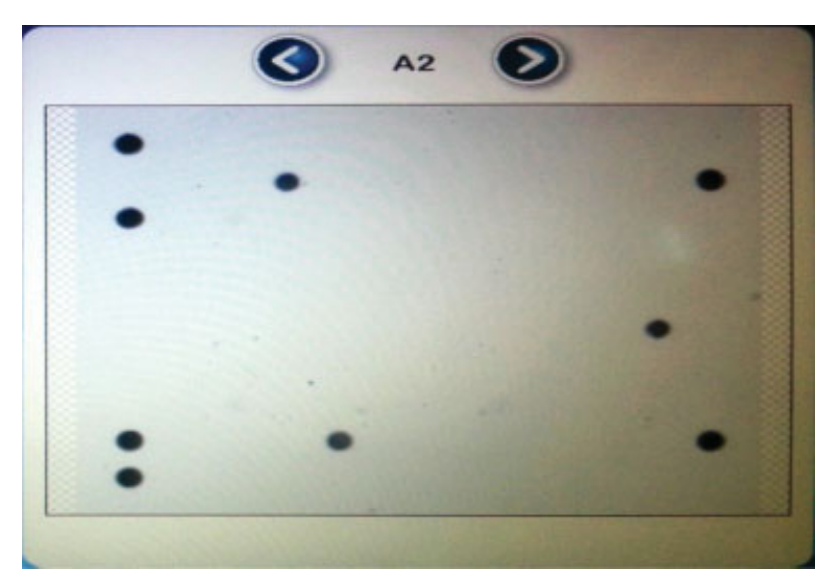

Fig. 2 Negative results of patients.

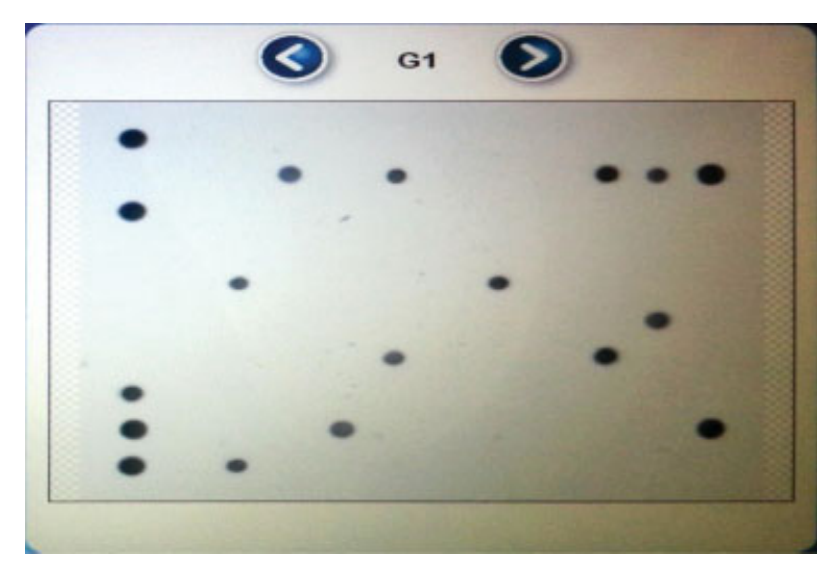

Fig. 3 Negative results of patients (influenza virus A [INF A] $\mathrm{H}_{3} \mathrm{~N}_{2}$ positivity).

\section{Discussion}

Viral RTIs are a significant societal health challenge as they lead to long hospital stays and even deaths, especially in children under the ages of 5 . We consider that knowing about the frequency and seasonal distribution of agents leading to viral RTIs in this age segment sheds light on the diagnosis and vaccination for healthcare professionals. ${ }^{11}$ In RTI-originated acute disorders, agents cannot be determined in general, and so most of the agents determined are considered to be viral. ${ }^{12}$ The effects witnessed on RTIs may display differences in terms of age segments, seasons, underlying disorders, and geographical regions. According to their incidences, however, RSV, INF, PIV 3, and AdV are reported as the agents ranking from highest to lowest. ${ }^{1}$

In our study performed with MPCR assay, we determined viral agents of acute RTIs and their percentages as RSV B (27.9\%), HRV (18.8\%), and RSV A (17.8\%) (-Table 1). In a similar study performed by Çiçek et al, ${ }^{10}$ three most frequently encountered pathogens were defined as RSV (11.0\%), HRV (5.6\%), and INF A (4.2\%). One thousand one hundred and twenty-six eligible children were enrolled in another prospective study from United States. A specific virus was

Table 1 Distribution of viral agents leading to acute respiratory tract infections

\begin{tabular}{|l|l|l|}
\hline Viruses & Number & Percentage (\%) \\
\hline RSV B & 341 & 27.9 \\
\hline HRV & 230 & 18.8 \\
\hline RSV A & 217 & 17.8 \\
\hline HMPV & 92 & 7.5 \\
\hline INF A (and subtypes) & 91 & 7.5 \\
\hline AdV & 88 & 7.2 \\
\hline INF B & 60 & 4.9 \\
\hline PIV 3 & 58 & 4.8 \\
\hline HCoV & 21 & 1.7 \\
\hline PIV 1 & 17 & 1.4 \\
\hline PIV 2 & 6 & 0.5 \\
\hline Total & 1,221 & 100 \\
\hline
\end{tabular}

Abbreviations: AdV, adenovirus; HCoV, human coronavirus; HMPV, human metapneumovirus; HRV, human rhinovirus; INF A/B, influenza virus $A / B$; PIV $1 / 2 / 3$, parainfluenza virus $1 / 2 / 3$; RSV $A / B$, respiratory syncytial virus $A / B$. 
4 Prevalence and Concomitancy of Respiratory Viruses in Children with Acute RTIs Tüzüner et al.

Table 2 Distribution of viruses with positivity more than one

\begin{tabular}{|l|l|l|}
\hline Viruses & Number & Percentage (\%) \\
\hline Double agents & 236 & 89.8 \\
\hline Triple agents & 18 & 6.8 \\
\hline Quaternary agents & 9 & 3.4 \\
\hline Total & 263 & 100 \\
\hline
\end{tabular}

identified in $61.0 \%$ of children, HMPV was identified in $9.0 \%$, second to RSV (45\%). ${ }^{13}$

Biçeret al, ${ }^{14}$ however, reported RSV (32\%) as the most frequent agent followed by AdV with $26.2 \%$ and PIV with $19.4 \%$. In another similar study performed by Akçalıet $\mathrm{al}^{15}$ RSV and HRV were reported as the most frequent agents with $61 \%$ and $35 \%$, respectively. In the study performed in children by Sancakliet $\mathrm{al}^{16}$, however, the most frequent agents were reported as HRV (26.4\%) and RSV A-B (10.3\%). Another study also found that $48.5 \%$ of agents causing lower RTIs were viral, and $44 \%$ of these originated from RSV. ${ }^{17}$ In another retrospective study with 2,044 pediatric patients in Russia, the most frequent RTI agents were identified as INFA (40\%) and INFB $(12 \%){ }^{18}$ In our study the total rate of INF viruses is $12.4 \%$. These rates may vary according to region and year.

In the study by Akkaya et al, ${ }^{19}$ RSV and HSV were emphasized as the most frequent viral agents in children. In the study by Hatipoğluet al, ${ }^{20}$ RSV (55.6\%) and PIV (27.8\%) were also found as the most frequent agents. In another study, however, the most frequent agents were reported to be INFA (25\%), HRV (20\%), and HMPV (10\%). ${ }^{21}$ As understood from these findings of studies conducted in different regions, different results were reported.

Viral RTIs demonstrating seasonal differences lead to epidemics that could change from year to year, especially in warm climates. RSVs are known to cause infections most in winter months, while HRVs are known to do so throughout the year. ${ }^{1,22}$ As consistent with those found in literature, similar results were obtained for RSV and HRV in our study, as well. Considering the rates of coinfections in our study, the con-

Table 3 Concomitancy of double agents with positivity

\begin{tabular}{|l|l|l|}
\hline Viruses & Number & Percentage (\%) \\
\hline RSV B-HRV & 33 & 14.0 \\
\hline RSV A-HRV & 16 & 6.8 \\
\hline PIV 3-HRV & 14 & 5.9 \\
\hline RSV A-RSV B & 13 & 5.5 \\
\hline RSV B-HMPV & 11 & 4.7 \\
\hline RSV A-HMPV & 10 & 4.2 \\
\hline RSV A-INF B & 10 & 4.2 \\
\hline Others & 129 & 54.7 \\
\hline Total & 236 & 100 \\
\hline
\end{tabular}

Abbreviations: HMPV, human metapneumovirus; HRV, human rhinovirus; INF B, influenza virus $B$; PIV 3, parainfluenza virus 3; RSV $A / B$, respiratory syncytial virus $A / B$.
Table 4 Monthly distribution of viruses with positivity

\begin{tabular}{|l|l|l|}
\hline Months & Number & Percentage (\%) \\
\hline January & 223 & 16.9 \\
\hline February & 217 & 16.4 \\
\hline March & 265 & 20.2 \\
\hline April & 158 & 12 \\
\hline May & 97 & 7.3 \\
\hline June & 108 & 8.2 \\
\hline July & 57 & 4.3 \\
\hline August & 44 & 3.3 \\
\hline September & 41 & 3.1 \\
\hline October & 36 & 2.7 \\
\hline November & 30 & 2.3 \\
\hline December & 44 & 3.3 \\
\hline Total & 1,320 & 100 \\
\hline
\end{tabular}

comitancy of RSV B-HRV was detected as $14 \%$. Akçalıet al ${ }^{15}$ report in their study that the concomitancy of RSV-HRV was found as the most widespread reason for coinfection, as parallel to our findings. Again, in another study by Frobert et $\mathrm{al}^{23}$ in children under the age of 2 in the intensive care unit, RSV (24.3\%) was reported to be the most frequently encountered agent in coinfections. Another prospective study was performed with 772 hospitalized infants. Fifty-nine patients had coinfection with RSV and HRV, RSV and AdV, INF and HRV, or AdV and HRV. ${ }^{24}$ In two other studies, the coinfection rates of HRV-EV were found to be higher, compared with other

Table 5 Distributions of most commonly detected viruses per month

\begin{tabular}{|l|l|l|l|}
\hline Months & RSV B & HRV & RSV A \\
\hline January & 118 & 23 & 21 \\
\hline February & 35 & 16 & 62 \\
\hline March & 66 & 24 & 76 \\
\hline April & 56 & 36 & 44 \\
\hline May & 13 & 18 & 8 \\
\hline June & 3 & 38 & 2 \\
\hline July & 2 & 6 & 1 \\
\hline August & 4 & 8 & 0 \\
\hline September & 1 & 12 & 1 \\
\hline October & 4 & 16 & 0 \\
\hline November & 2 & 15 & 1 \\
\hline December & 37 & 18 & 1 \\
\hline Total & 341 & 230 & 217 \\
\hline
\end{tabular}

Abbreviations: HRV, human rhinovirus; RSV A/B, respiratory syncytial virus $A / B$. 
agents. ${ }^{25,26}$ As seen in all these studies, why viruses lead to coinfections still remains unclear. ${ }^{27}$

The importance of respiratory viruses as the etiologic agent of RTIs in children was verified in our study. In $58.2 \%$ of the children admitted to our hospitals with the complaint of acute RTIs, the major pathogen was seen as virus. Our study summarizes the clinical characteristics of viral agents that were detected in children with RTI. The severity of diseases caused by RSV B, HRV, and RSV A were higher than other viruses. Coinfections were detected in $19.9 \%$ of the patients, especially with some pathogens, such as RSV, HRV, and PIV, whereas, AdV and HCoV were more commonly identified as single infections. The presence of coinfections was not associated with increased disease severity. RSV exhibited seasonal patterns; cases peaking over the rainy season (DecemberApril), and HRV were endemic throughout the year. It was concluded that MPCR is beneficial for physicians to diagnose such viruses at an early stage. By the early detection of respiratory viruses leading to seasonal epidemics, physicians' approach to patients will become easier, and unnecessary use of antibiotics will be prevented. Additionally, our study findings are intriguing in shedding light on studies related to the development and application of vaccines.

\section{Conflict of Interest}

None.

\section{References}

1 Kesson AM. Respiratory virus infections. Paediatr Respir Rev 2007; 8(3):240-248

2 WHO Recommended Surveillance Standards. Second edition, p.131. Available at: http://www.who.int/csr/resources/publications/surveillance/whocdscsrisr992.pdf. Accessed date 15 July, 2016

3 Akşit S. Acute Respiratory Tract Infections-1. STED 2002; 11:132-135

4 Tregoning JS, Schwarze J. Respiratory viral infections in infants: causes, clinical symptoms, virology, and immunology. Clin Microbiol Rev 2010;23(1):74-98

5 Abedi GR, Prill MM, Langley GE, et al. Estimates of parainfluenza virus-associated hospitalizations and cost among children aged less than 5 years in the United States, 1998-2010. J Pediatric Infect Dis Soc 2016;5(1):7-13

6 Turhan V, Mert G, Kılıç A, et al. Investigation of clinical relevance of bacterial colonization in patients with suspected viral respiratory tract infection by using multiplex PCR method. Dis Mol Med 2013; $1(1): 2-7$

7 Brunstein J, Thomas E. Direct screening of clinical specimens for multiple respiratory pathogens using the Genaco Respiratory Panels 1 and 2. Diagn Mol Pathol 2006;15(3):169-173

8 Advani S, Sengupta A, Forman M, Valsamakis A, Milstone AM. Detecting respiratory viruses in asymptomatic children. Pediatr Infect Dis J 2012;31(12):1221-1226

9 Vallières E, Renaud C. Clinical and economical impact of multiplex respiratory virus assays. Diagn Microbiol Infect Dis 2013;76(3): 255-261
10 Çiçek C, Arslan A, Saz EU, et al. Simultaneous detection of respiratory viruses using multiplex PCR method in patients with upper and lower respiratory tract infections (in Turkish). Ege J Med 2015; 54(1):8-14

11 Nair H, Brooks WA, Katz M, et al. Global burden of respiratory infections due to seasonal influenza in young children: a systematic review and meta-analysis. Lancet 2011;378(9807): 1917-1930

12 Louie JK, Hacker JK, Gonzales R, et al. Characterization of viral agents causing acute respiratory infection in a San Francisco University Medical Center Clinic during the influenza season. Clin Infect Dis 2005;41(6):822-828

13 Anderson EJ, Simões EAF, Buttery JP, et al. Prevalence and characteristics of human metapneumovirus infection among hospitalized children at high risk for severe lower respiratory tract infection. J Pediatric Infect Dis Soc 2012;1(3):212-222

14 Biçer S, Giray T, Çöl D, et al. Virological and clinical characterizations of respiratory infections in hospitalized children. Ital J Pediatr 2013;39:22

15 Akçalı S, Yılmaz N, Güler Ö, et al. Frequency of respiratory viruses in children with lower respiratory tract infection (in Turkish). Turk Arc Ped 2013:215-20

16 Sancaklı Ö, Yenigün A, Kırdar S. Results of polymerase chain reaction in nasopharyngeal swab specimens of patients with lower respiratory tract infection (in Turkish). J Pediatr Inf 2012; 6:84-89

17 Nathan AM, Rani F, Lee RJY, et al. Clinical risk factors for lifethreatening lower respiratory tract infections in children: a retrospective study in an urban city in Malaysia. PLoS ONE 2014;9(10): e111162

18 Bulgakova VA, Uchaikin VF, Shamsheva OV, et al. Pharmacological and epidemiological study of the course of influenza and other acute respiratory viral infections in postpandemic season in children under the age of 18. Pediatr Infect Dis 2015;10(3):68-75

19 Akkaya O, Feyzioğlu B, Özdemir M, et al. The investigation of pneumonia viruses by multiplex PCR in patients with pneumonia. J. Microbiol Biotech Res 2014;4(2):22-26

20 Hatipoğlu N, Somer A, Badur S, et al. Viral etiology in hospitalized children with acute lower respiratory tract infection. Turk J Pediatr 2011;53(5):508-516

21 Brittain-Long R, Nord S, Olofsson S, Westin J, Anderson LM, Lindh M. Multiplex real-time PCR for detection of respiratory tract infections. J Clin Virol 2008;41(1):53-56

22 Bayrakdar F, Altaş AB, Korukluoğlu G. Seasonal distribution of the respiratory tract viruses in Turkey between 2009-2012 (in Turkish). J Turkish Soc Microbio 2013;43(2):56-66

23 Frobert E, Escuret V, Javouhey E, et al. Respiratory viruses in children admitted to hospital intensive care units: evaluating the CLART Pneumovir DNA array. J Med Virol 2011;83(1):150-155

24 Aberle JH, Aberle SW, Pracher E, Hutter HP, Kundi M, PopowKraupp T. Single versus dual respiratory virus infections in hospitalized infants: impact on clinical course of disease and interferongamma response. Pediatr Infect Dis J 2005;24(7):605-610

25 Forman MS, Advani S, Newman C, Gaydos CA, Milstone AM, Valsamakis A. Diagnostic performance of two highly multiplexed respiratory virus assays in a pediatric cohort. J Clin Virol 2012; 55(2):168-172

26 Asner SA, Petrich A, Hamid JS, Mertz D, Richardson SE, Smieja M. Clinical severity of rhinovirus/enterovirus compared to other respiratory viruses in children. Influenza Other Respi Viruses 2014;8(4):436-442

27 Goka EA, Vallely PJ, Mutton KJ, Klapper PE. Single and multiple respiratory virus infections and severity of respiratory disease: a systematic review. Paediatr Respir Rev 2014;15(4):363-370 